
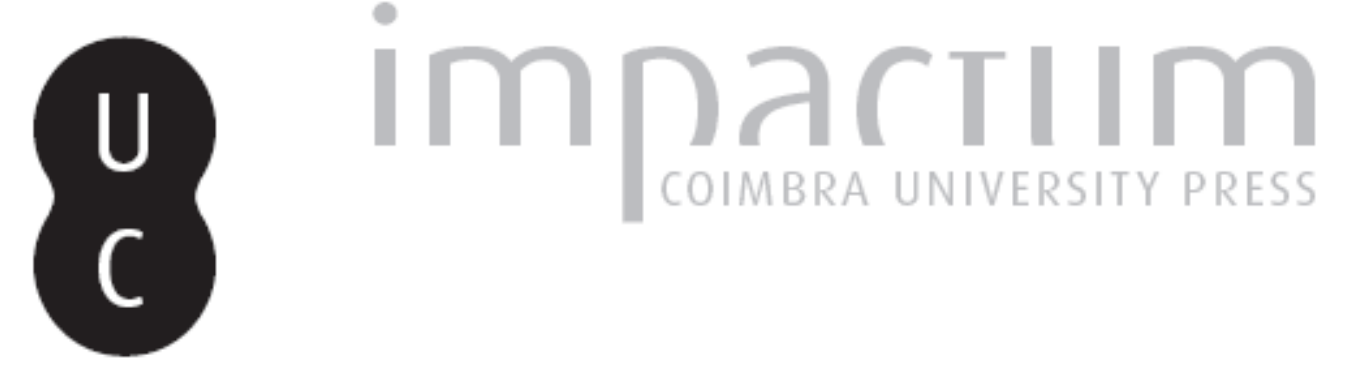

\title{
Das relações quinhentistas entre loannes e Olavus Magnus e Damião de Góis após a sua permanência em Pádua (em Vicenza e em eventuais deslocações a Veneza)
}

Autor(es): $\quad$ Matos, Manuel Cadafaz de

Publicado por: Imprensa da Universidade de Coimbra

URL persistente:

URI:http://hdl.handle.net/10316.2/42687

DOI:

DOI:https://doi.org/10.14195/0870-8584_1_6

Accessed : $\quad$ 26-Apr-2023 14:37:07

A navegação consulta e descarregamento dos títulos inseridos nas Bibliotecas Digitais UC Digitalis, UC Pombalina e UC Impactum, pressupõem a aceitação plena e sem reservas dos Termos e Condições de Uso destas Bibliotecas Digitais, disponíveis em https://digitalis.uc.pt/pt-pt/termos.

Conforme exposto nos referidos Termos e Condições de Uso, o descarregamento de títulos de acesso restrito requer uma licença válida de autorização devendo o utilizador aceder ao(s) documento(s) a partir de um endereço de IP da instituição detentora da supramencionada licença.

Ao utilizador é apenas permitido o descarregamento para uso pessoal, pelo que o emprego do(s) título(s) descarregado(s) para outro fim, designadamente comercial, carece de autorização do respetivo autor ou editor da obra.

Na medida em que todas as obras da UC Digitalis se encontram protegidas pelo Código do Direito de Autor e Direitos Conexos e demais legislação aplicável, toda a cópia, parcial ou total, deste documento, nos casos em que é legalmente admitida, deverá conter ou fazer-se acompanhar por este aviso.

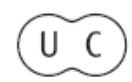




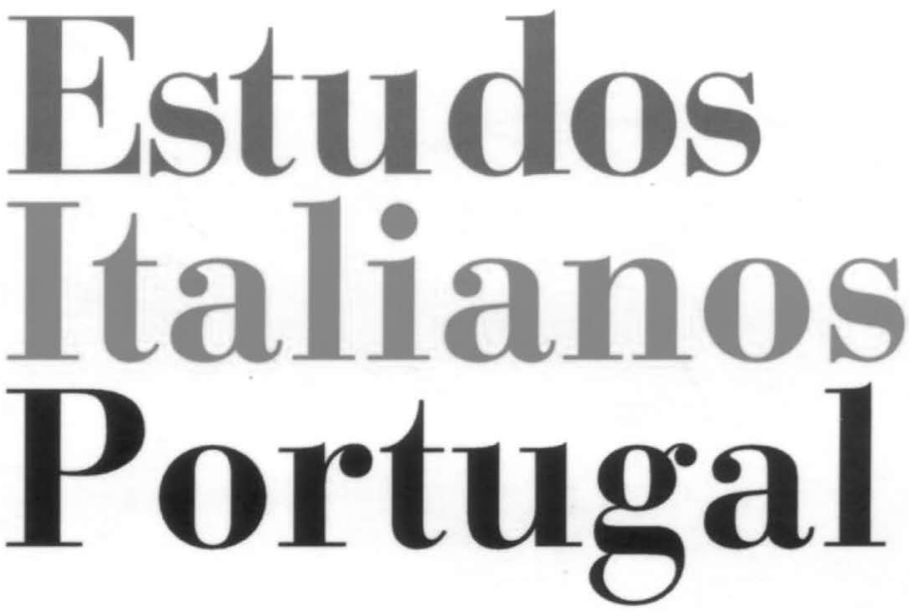

Instituto

Italiano

de Cultura

em Portugal

Nova Série

$\mathbf{N}^{\circ} \mathbf{1}$

2006 
DAS RELACCÕES QUINHENTISTAS

ENTRE IOANNES E OLAVUS MAGNUS

E DAMIÃO DE GÓIS APÓS A SUA PERMANÊNCIA

EM PÁDUA (EM VICENZA E EM EVENTUAIS

DESLOCAÇÕES A VENEZA)

Manuel Cadafaz de Matos

Desde a Chegada a Itália de Ioannes Magnus, Arcebispo de Upsala (Suécia) no exílio, e de seu irmão Olavus Magnus, que se encontram relativamente bem documentados não só os espaços das suas vivências como as principais acções desenvolvidas nesse período. Os caminhos dos dois irmãos suecos por terras transalpinas são ainda melhor conhecidos desde que Brita Larsson publicou o roteiro da epistolografia conhecida do primeiro ${ }^{1}$.

Os elementos em presença indicam que em 1538 - portanto cerca de uma década depois de ter conhecido em Dantzig, por intermédio de João Dantisco ${ }^{2}$, o humanista português Damião de Góis - Ioannes Magnus já se encontrava com seu irmão a viver de novo em Itália.

1 Brita Larsson, Johanne's Magnus' Latin Letters. A Critical Edition with Introduction and Commentary, Lund, 1992. Devem-se acrescentar, porém, às cartas aí apresentadas, as duas que Ioannes Magnus enviou de Roma, no final da sua vida (na década de quarenta), a Damião de Góis.

2 João Dantisco foi embaixador da Polónia junto da corte imperial e também ele se relacionou com Damião de Góis. Entre outras acções que levou a cabo conta-se a de ter sido um dos humanistas que tentaram (na expressão de Amadeu Torres, As Cartas de Damião de Góis, I, Paris, Centro Cultural Português, da Fundação C. Gulbenkian, 1982, p. 301, n. 1), de forma directa ou indirecta, "reconduzir Melanchthon ao seio da Igreja". 


\section{Do encontro de Góis com os irmãos Magnus na CIDADE TRANSALPINA DE ViCENZA}

Um dos primeiros testemunhos conhecidos que atestam sobre a primeira fase da permanência do titular do "arcebispado" de Upsala ${ }^{3}$ (ante os olhos de Roma) ${ }^{4}$ na zona levantina de Itália é a carta que escreveu de Veneza, datada de 20 de Dezembro de 1538, já depois da fase inicial da sua permanência em Roma ${ }^{5}$, dirigida precisamente a João Dantisco. A sua última epístola escrita nesta mesma cidade levantina é de 13 de Julho de 1539 e foi remetida ao magistrado superior e conselheiros de Gdansk.

Estes dois aristocratas e religiosos - homens de errância como já referimos - sobreviviam, na cidade do Adriático, graças à generosidade e à ajuda material ${ }^{6}$ do Patriarca Hieronymis Quirinus ${ }^{7}$ que os acolheu durante vários meses.

\footnotetext{
3 Não sendo conhecido um retrato de Ioannes Magnus desse período, reproduz-se a sua efígie tal como surge na obra de Noberg, De meritis et fatis Joannis et Olai Magnorum, Upsala, 1741 (reprodução esta apresentada por Brita Larsson, in edição ant. cit., p. 14).

${ }^{4}$ O Papa Clemente VII, segundo Jean-Marie Maillefer, aceitou validar a eleição de Johannes Magnus para o Arcebispado de Upsala em 1533. Esta decisão, porém, chegou lá demasiado tarde. Esse religioso e seu irmão Olavus tinham deixado a Suécia no ano anterior e Gustavo Vasa tinha já feito designar para esta sede um arcebispo luterano, o que impossibilitou Johannes Magnus de regressar ao seu país para assumir aquele cargo e dignidade. Remete-se para Jean-Marie Maillefer, Olaus Magnus, Histoire et Description des Peuples du Nord, Paris, Les Belles Lettres, col. "Les Classiques du Nord", 2004, p. 11.

${ }^{5}$ Sabe-se que já em 13 de Janeiro desse ano de 1538 Johannes Magnus se encontrava em Roma (data da sua primeira carta de Itália). Nessa cidade foi encontrar um conjunto de humanistas escandinavos que aí residiam. Era o caso do sueco Peder Mänsson (que dirigia na capital transalpina, desde 1508, a Casa de Santa Brígida), ou o antigo Arcebispo da Noruega Erik Valkendorf.

${ }^{6}$ Jean-Marie Maillefer, op. cit., p. 11.

Jan Morris, in The Venetian Empire. A Sea Voyage, Londres, Faber and Faber, 1980 , p. 52, faz alusão a um membro do clã veneziano Querinis como tendo tomado posse de Stampalia. Os elementos detectados impossibilitam-nos de poder concluir tratar-se deste Patriarca que acolheu os irmãos Magnus da Suécia.
}

Antes de chegarem a Veneza tinham estado algum tempo em Vicenza. E foi nessa cidade de Vicenza que foram, efectivamente, reactivados os contactos pessoais entre Damião de Góis e Ioannes Magnus e seu irmão Olavus. Vejamos em que circunstâncias tal sucedeu.

Esse encontro verificou-se, como já foi assinalado também por Jean Aubin, entre Maio e meados de Setembro de $1538^{8}$, um tanto "inopinadamente" 9 , na referida cidade de Vicenza. Assinale-se que os dois irmãos tinham-se deslocado a essa cidade com o objectivo de participarem nos trabalhos do concílio que aí teve lugar nesse ano ${ }^{10}$, e cujos trabalhos se iniciaram, segundo regista Brita Larsson ${ }^{11}$, em 12 de Maio.

${ }^{8} \mathrm{Na}$ cronologia da correspondência de Ioannes Magnus fixada por Brita Larsson, existem duas cartas escritas por Ioannes Magnus nessa cidade, uma de 30 de Maio de 1538, dirigida a João Dantisco; e uma outra, por sinal redigida no mesmo dia, enviada ao Magistrado superior e conselheiros de Gdansk.

9 Jean Aubin, "Damião de Góis et l'Archevêque d'Upsal", in Damião de Góis, Humaniste Européen, coordenação e apresentação de José V. de Pina Martins, edição ant. cit., Braga, Barbosa e Xavier Ltda., 1982, pp. 245-330, em particular p. 286. Este texto foi republicado, como é sabido, in Le Latin et l'Astrolabe. Recherches sur le Portugal de la Rennaissance, son Expansion en Asie et les relations internationales, Lisboa-Paris, Centre Culturel Calouste Gulbenkian, Comissão Nacional para as Comemorações dos Descobrimentos Portugueses, 2 vols., vol. I, pp. 237-307 (sendo esta passagem em particular referenciada na nova edição in p. 269). Jean Aubin crê que o facto de Damião de Góis referir ter encontrado "inopinadamente", em Vicenza, os dois aristocratas e religiosos da Suécia, pode deixar antever que as relações entre eles tenham, até aí, estado um pouco descuradas. Não será essa uma das razões por que ambos se passaram a encontrar (uma ou mais vezes, não o sabemos) na cidade de Veneza, onde poucas semanas depois já se encontravam a viver na residência do Patriarca Hieronymus Quirinus? Estamos em crer que sim.

${ }^{10}$ L. Pastor, History of the Popes, edição de R. F. Kerr, t. XI, 1923, p. 115. Regista, entretanto, Jean-Marie Maillefer, in ed. ant. cit. (2004), p. 11, que já em 1537 os dois irmãos tinham participado nos trabalhos do Concílio de Mântua.

11 Brita Larsson, op. cit., p. 126, n. 13. Esta investigadora da universidade de Lund estabelece que os dois irmãos tinham chegado a essa cidade transalpina alguns dias antes, ou seja, em 30 de Abril. 


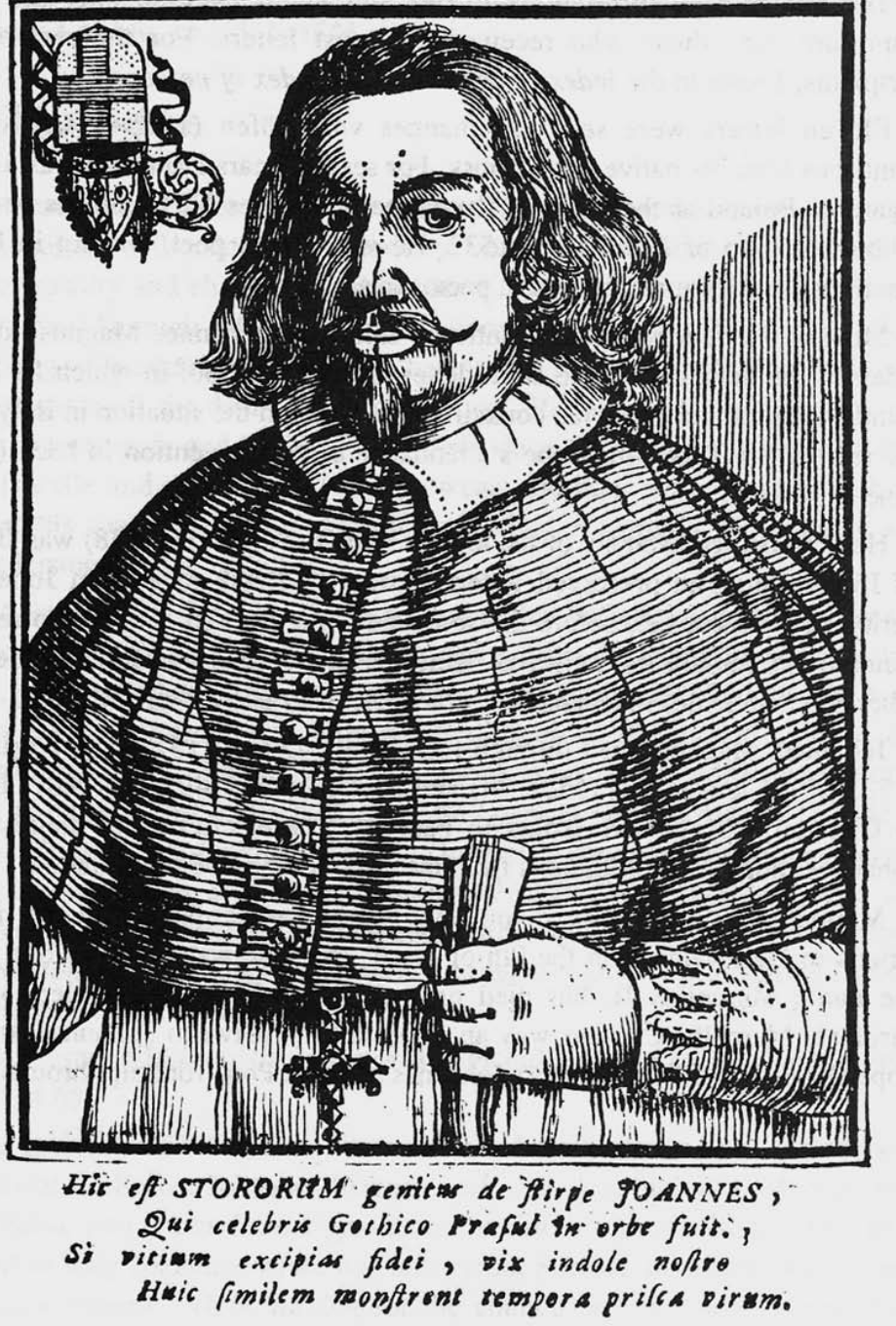

A fisionomia de Ioannes Magnus (não sendo conhecido o seu retrato desta fase da sua vida em Itália) pode ser perspectivada nesta reprodução do século XVIII; à direita, manuscrito de uma das suas epístolas autógrafas, de 1532

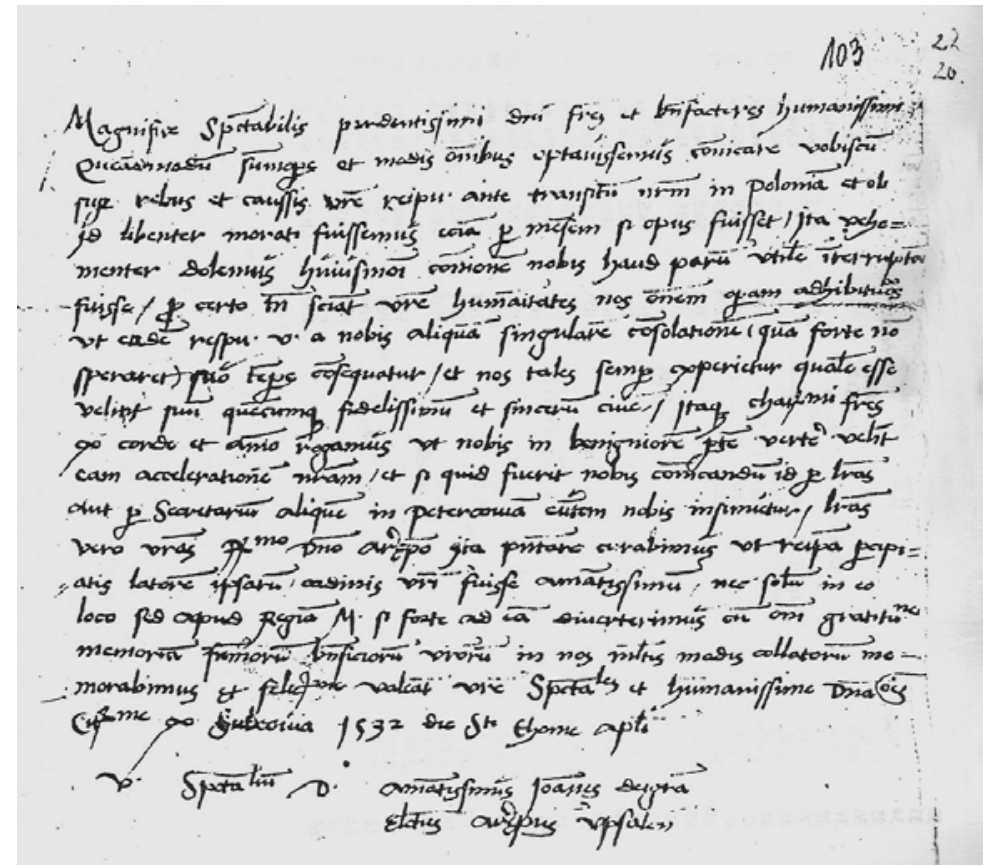

Interrogamo-nos, até, se não terá sido então que ele captou de Olavus Magnus essa premissa do seu pensamento no sentido da proximidade ideológica entre os povos da Abissínia e da Lapónia ${ }^{12}$ (de que aquele, aliás, veio a dar mais tarde testemunho na sua obra Historia de gentibus septentrionalibus, só editada em Roma em 1555, como afirmamos noutro passo deste nosso trabalho).

Durante essa permanência em Veneza, Olavus Magnus teve ensejo de concluir a preparação da sua Carta Gothica,

12 É bem provável que neste período Damião de Góis - na altura em que já desenvolvia estudos com vista à redacção da sua obra Fides, Religio Moresque..., editada poucos meses depois já na Flandres - tenha tomado contacto e estudado a obra Schondia, de Jacob Ziegler (com edição de Estrasburgo, de 1532), onde colheu também inspiração para o seu texto da Descrição da Lapónia. 
também referenciada por Carta Marina et Descriptio septentrionalium terrarum ac mirabilium rerum in eis contentarum diligentissime elaborata.

\section{A Carta Gothica - Carta Marina, de Olavus} MagnUS, A PRIMEIRA A REFLECTIR EM PORMENOR AS REGIÕES NÓRDICAS

Trata-se (no que vários autores estão efectivamente de acordo) da primeira carta moderna e em pormenor da Europa do Norte, compreendendo inclusivamente as regiões da Islândia e da Groenlândia. Jean-Marie Maillefer estabelece que ela se baseia nas próprias observações do autor, "e não apenas nas compilações mais antigas, como sucedia com as cartografias anteriores, tal como a Schondia, de Jacob Ziegler, de $1532 " 13$.

Não sendo então ainda o seu nome conhecido dos impressores venezianos, é provável que não lhe tenha sido fácil chegar a acordo para que lhe fosse impressa esta carta geográfica. Poderá, neste domínio específico, ter sido até a intercessão de Hieronymus Quirinus que possibilitou que esta sua empresa particular - o da impressão desta sua obra seguisse por diante.

Fosse como fosse, o que é certo é que em 1539 - e nessa altura tudo indica que Damião de Góis já se encontrasse de regresso à Flandres e à feitoria portuguesa - essa Carta Gothica foi efectivamente impressa naquela cidade. Tratou-se de uma obra composta de nove folhas, com uma dimensão total de 1,70 $\mathrm{m}$ por $1,20 \mathrm{~m}$.

Esta Carta Gothica integrava dois tipos de comentários, em separado. Um deles era, como o público de leitores a atingir naquela região o recomendava, em língua italiana,

${ }^{13}$ Jean-Marie Maillefer, loc. cit. ou seja em vulgar: Opera breve, laquale demonstra, e dechiara, ouero da il modo facile de intendere la charta, ouer delle terre frigidissime di Settentrione ${ }^{14}$. O segundo comentário - e havia outros tipos de preocupações do autor que o levavam a proceder neste sentido - era em língua alemã.

Importa assinalar, efectivamente, que datava já de 1527 , ou seja, da permanência dos irmãos Olavus e Ioannes Magnus em Danzig, o começo da preparação desta carta geográfica. Não esquecendo este facto, Olavus não só redigiu uma parte dos seus comentários em alemão como dedicou a carta aos conselheiros $^{15}$ de Danzig.

A Carta Gothica, impressa como dissemos em Veneza em 1539, foi mais tarde reutilizada - embora com algumas variações - inserida no conjunto das 476 imagens ${ }^{16}$ que decoram a obra de Olavus Magnus, Historia de gentibus septentrionalibus ${ }^{17}$, impressa em Roma, em $1554^{18}$. Foi ainda redifundida, na mesma cidade, em 1572, dois anos depois de Ortelius voltar a editar em Antuérpia os elementos nela constantes.

${ }_{14}$ Remete-se para o estudo de Carla Cucina, "Literae Aquilonarium Antiquiores. Le Rune in Johannes e Olaus Magnus fra prospectia antiquaria e tradizione etnica", in I Fratelli Giovanni e Olao Magno, Opera e cultura tra due mondi, a cura di Carlo Santini, Roma, Il Calamo, 1999, pp. 33-100, em particular p. 33 (n. 1) e p. 36 (n. 6).

${ }^{15}$ A expressão francesa usada neste contexto por Jean-Marie Maillefer é "échevins" a qual, mais traduzida à letra, pretende significar "almotacés" daquela cidade germânica.

16 Deste conjunto de 471 gravuras, pode referir-se que apenas 461 eram originais e que as restantes, segundo regista Peter Gillren (no estudo cit.) tiveram mais de uma utilização. O mesmo investigador sublinha que desse conjunto de gravuras, entre 20 e 25 ostentam nítidas afinidades com algumas outras que se apresentam na ilustração da Bíblia, por Hans Holbein o Jovem, editada em 1538.

${ }_{17}$ Peter Gillgren, "The artist Olaus Magnus, vision and Illustration", in I Fratelli Giovanni e Olao Magno, pp. 147-155, em particular p. 147.

${ }^{18}$ Esta obra encontra-se referenciada por H. M. Adams, in Catalogue of Books Printed on the Continent of Europe, 1501-1600 in Cambridge Libraries, Cambridge, Cambridge University Press, 1967, (2 vols.), sob o n. ${ }^{\circ} 140$ (p. 698). 
Surgiam agora refundidos em novo tratamento cartográfico ${ }^{19}$ e antes de no período seiscentista voltar a ser tratada a cartografia sueca de uma forma diferenciada ${ }^{20}$.

Essa carta nórdica viu a luz da publicidade nessa zona do Adriático onde a actividade tipográfica local tinha vertentes preferenciais, a do petrarquismo ${ }^{21}$, a do platonismo e a do

${ }_{19}$ Remete-se para Paul Binding, Imagined Corners. Exploring the World's First Atlas, Londres, Headline Book Publishing, 2003, pp. 217-219 (mapa e respectiva descrição sumária), onde o autor estabelece que, para o Theatrum Orbis Terrarum, Ortelius se serviu, entre outras fontes, "da carta Scandia, de 1539, de Olaus Magnus",

${ }^{20}$ O cartógrafo sueco Anders Bure de Boo (1571-1646) viria, no século seguinte, a dar um novo incremento às representações geográficas daquela região. Em 1626, com efeito - portanto, quase um século depois de Olavus Magnus ter editado em Veneza a Carta Gothica -, Anders Bure de Boo publicou a carta intitulada Orbis Arctoi nova et accurata delineatio. Este mapa, em seis folhas, é considerado "a pedra angular da cartografia escandinava". Assinale-se que ficou então a dever-se àquele cientista a publicação de uma geografia histórica da Suécia. Dois anos depois aquele autor "instituiu para Gustavo Adolfo [Gustavo II] um serviço de levantamentos topográficos da Suécia, o Svenska Lantmäteriet, à testa do qual permaneceu, criando os fundamentos e linhas de orientação dos levantamentos terrestres, e que se manteve durante os primeiros duzentos anos da sua história”. Esta carta de Anders Bure de Boo da Suécia veio a influenciar decisivamente a representação da mesma região no Atlas de Joan Blaeu, publicado pela primeira vez na Holanda em 1662. Remete-se, a este respeito, para Joan Blaeu, Grande Atlas do Mundo, introdução de John Goss (publicado em colaboração com a Real Sociedade Geográfica de Londres), Lisboa, Verbo, 1990, pp. 32-33.

21 Para nos cingirmos apenas à componente da difusão tipográfica do petrarquismo neste período, bastará referir que neste mesmo ano de 1539 foi publicada nessa cidade, na oficina de João Giolito de Ferrara - e pelas mãos do literato Nicolò Franco -, uma obra que conheceu então uma particular difusão, intitulada Il Petrarchista, Dialogo (...) nel qual si scuoprono nuovi Secreti sopra il Petrarca. E si danno a leggere molte lettere, che il medemo Petrarca, in lingua Thoscana scrisse a diverse persone. Cose rare, ne mais piu date a luce. Remetemos a propósito de uma análise sucinta desta obra (acabada de imprimir em Outubro de 1539) para o estudo de Amedeo Quondam, "Petrarquistas e Gentis-Homens", in Petrarca 700 Anos, coordenação de Rita Marnoto, Coimbra, Instituto de Estudos Italianos, Faculdade de Letras (série "Leonardo"), 2005, pp. 187-248, em particular pp. 187-191

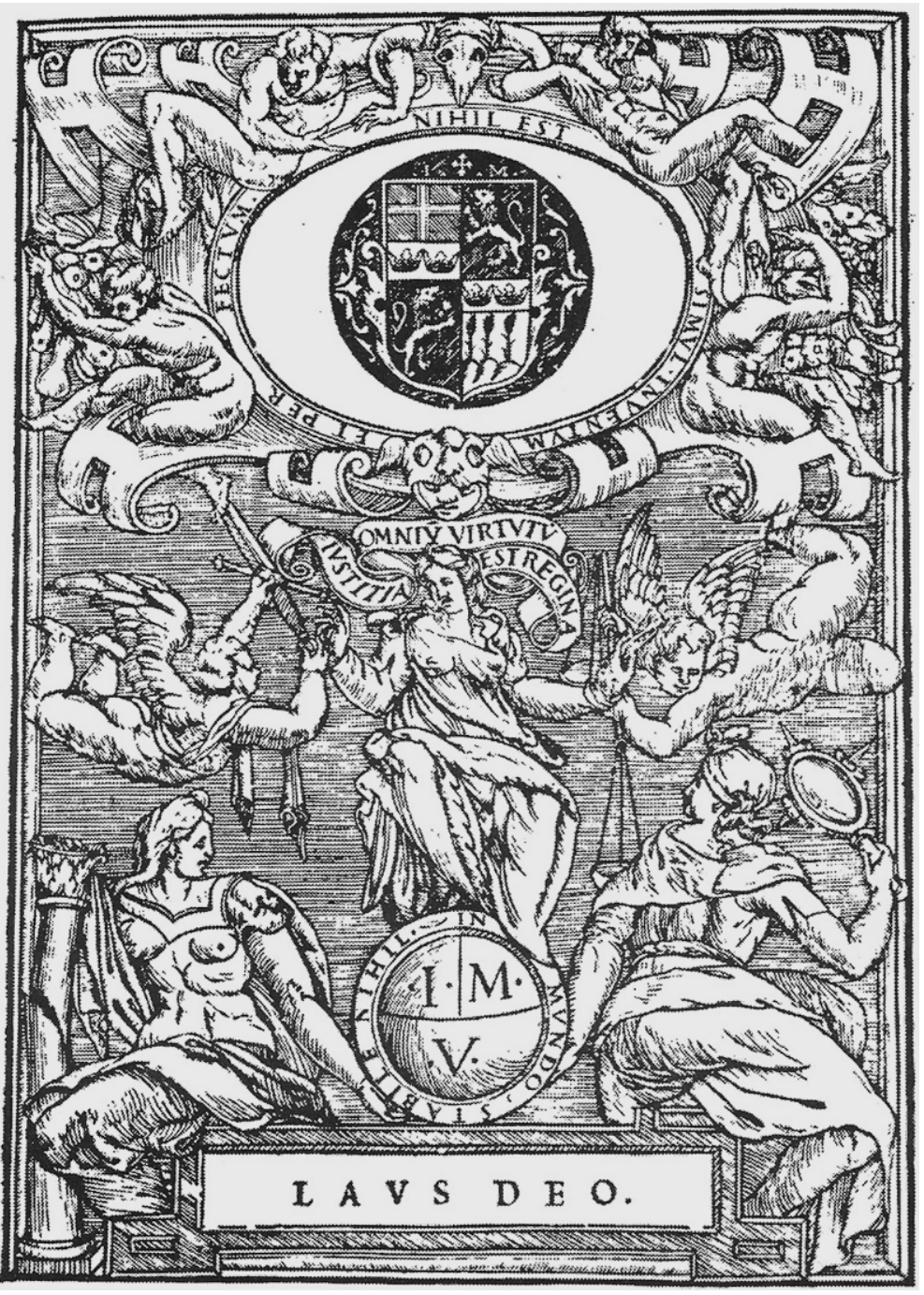

A Carta Marina ou Carta Gothica, de Olavus Magnus, foi de novo dada à estampa, em edição reduzida, na obra do autor Historia de gentibus septentrionalibus; ao fundo, centrada, na moldura, encontra-se a inscrição das iniciais do tipógrafo Ioannem Mariam de Viottis 


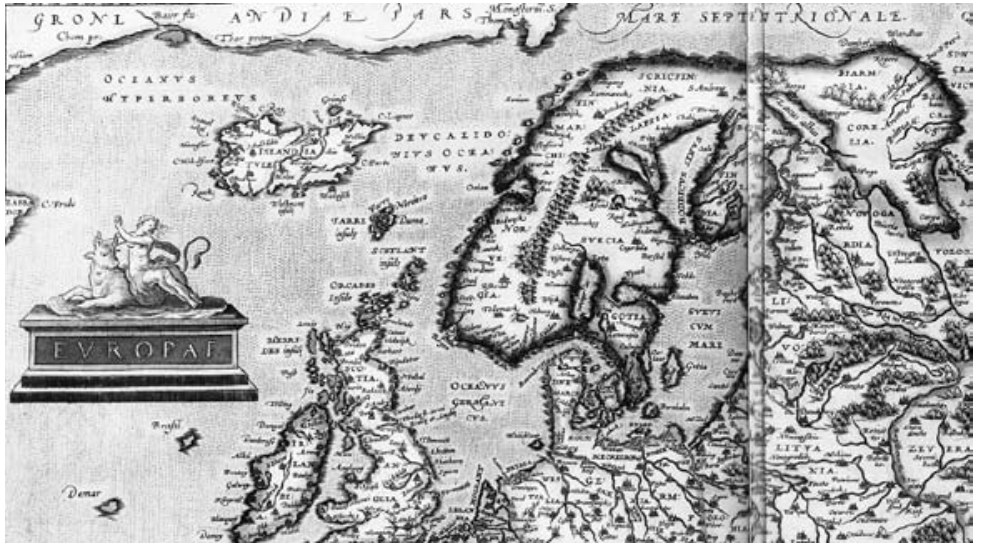

Pormenor da carta da Escôndia [Escandinávia], seguindo fielmente os elementos da Carta Gothica de Olavus Magnus, tal como surge na edição de Theatrum Orbis Terrarum, de Ortelius, na Flandres, em 1570

aristotelismo $^{22}$ renascentistas. Tal representação geográfica pelo impresso - já reproduzida anastaticamente ${ }^{23}$ e que na segunda metade do século XX beneficiou do estudo de

22 Remete-se a respeito desta vertente para Manuel Cadafaz de Matos, "Unidade e diversidade das edições impressas, de e sobre Aristóteles, entre os séculos XV e XVI", cuja primeira parte (referente à produção tipográfica veneziana das últimas décadas do século XV) foi dada à estampa no volume A Apologia do Latim. In Honorem Dr. Miguel Pinto de Meneses (1917-2004), vol. I, Lisboa, Edições Távola Redonda/Centro de Estudos de História do Livro e da Edição, 2005, pp. 251-282. - Assinale-se ainda que Olavus Magnus, na sua edição (já atrás referida), Historia de gentibus septentrionalibus, no século XVI, denota a preocupação de reflectir sobre a obra de Aristóteles, detendo-se a dado passo desse seu tratado na Historia Animalium desse filósofo, em particular nos livros VIII-XI. Veja-se, a este respeito, o estudo de Giuseppe Flammini, "La prefatio all'Historia de gentibus septentrionalibus nella tradizione del genere proemiale", in I Fratelli Giovanni e Olao Magno, pp. 117-137, em particular p. 122.

${ }^{23}$ Cfr. Carta Gothia ou Carta Marina, reestampada em fac-símile pela Lychnos Bibliotek (11:1), Malmö, 1949; ou, ainda, E. Lynam, "The Carta Marina of Olaus Magnus, Veneza, 1539 \& Roma, 1572, Jenkintown, 1949, pp. 2, 17-19, 22 e $24-26$. alguns investigadores ${ }^{24}$ - resultou, como atrás se disse, de uma vivência pelo menos numa parte significativa das regiões descritas.

Na parte que aqui mais interessa, a da região da Lapónia, a não esquecer que nos anos de 1518-1519 Olavus Magnus tinha empreendido uma longa e agreste missão, como legado eclesiástico, por essas paragens ${ }^{25}$. Foi essa acção que lhe permitiu - pelo primado da experiência ${ }^{26}$ - registar com tamanha propriedade tais observações.

Poderá muito bem ter-se concretizado, a nosso ver, a hipótese de Góis haver reactivado relações (depois do encontro em Vicenza) - na residência do Patriarca Hieronymis Quirinus em Veneza, em 1538 - com Olavus e com Ioannes Magnus. Afigura-se possível, pois - e afirmamo-lo aqui, cientes de que tais afirmações se observam, apenas, num plano conjectural -, que as suas eventuais trocas de informações pudessem também ter perspectivado outras questões de interesse comum, por exemplo, alguns aspectos relacionados com a presença de europeus em terras da Ásia.

Tanto no período da permanência destes dois irmãos em Vicenza, como no das suas estadias em Veneza, a epistolografia do Arcebispo de Upsala é deveras elucidativa das suas acções, tanto num plano espiritual como cultural. Remete-se, a este respeito, para o Índice que apresentamos como Anexo I.

24 É o caso de H. Richter, "Olaus Magnus Carta Marina 1539", Lychnos Bibliotek (11:2), Lund, 1967 (onde o autor reproduz, de novo, esta carta geográfica); ou de H. Grape, "Carta Marina som resejournal”, in Norbotten, 1971, pp. 89-128.

${ }_{25}$ H. Grape, in "Carta Marina som resejournal" (estudo referenciado na nota anterior), publica, in p. 93, um mapa referente aos itinerários então seguidos nessas paragens e em tal período por Olavus Magnus.

${ }^{26}$ Este primadio foi mais tarde teorizado por Camões na estrofe de Os Lusíadas onde afirma "vi, claramente visto". 
3. Da RedacÇão E ANOtaÇÕes, POR IoAnnes Magnus, do códice De mirabilis orientalium, por Marco Polo

Assinale-se que Ioannes Magnus - que, proveniente da Suécia, chegara pela primeira vez a Roma em 1517 - tinha terminado em Agosto de 1520, na residência de Santa Brígida, naquela cidade, a redacção de um autógrafo das viagens de Marco Polo que chegou até aos nossos dias. Trata-se do manuscrito que ostenta esta assinatura: Johannes Magnus Gothus Lincopensis Anno domini 1520, per mensem Augusti scripsitn Romae in domo sancte Brigitte ${ }^{27}$ (ao qual já fizemos, atrás, uma alusão sumária).

Este autógrafo de Ioannes Magnus conserva-se hoje na Biblioteca Vaticana (onde já o consultámos) e apresenta $73 \mathrm{fls}^{28} \mathrm{O}$ autor, porém, não se limitou a copiar um dos vários testemunhos daquela fonte então disponíveis em bibliotecas e/ou arquivos daquela cidade. Fez acompanhar a sua cópia das mais variadas anotações, ou seja de apostilhas em que ia estabelecendo os comentários que uma ou outra passagem lhe ia suscitando à medida que avançava no seu trabalho.

O texto latino por si fixado, De mirabilibus orientalium regionum, também por vezes designado por Il Milione ${ }^{29}$, poderá suscitar, aqui, ainda algumas considerações. Importará, primeiramente, situar esse texto nas várias tipologias essenciais de testemunhos que o fizeram chegar até esse período do

27 Eva Nilsson Nylander, "Johannes Magnus and Marco Polo. An autograph manuscript in the Vatican Library", in I Fratelli Giovanni e Olao Magno, pp. 177-185, em particular, p. 178.

${ }^{28}$ No aludido estudo (referenciado na n. anterior), Eva Nilsson Nylander estabelece, in p. 181, que Johannes Magnus deverá ter-se ocupado, durante cerca de um mês, na preparação desta cópia.

${ }^{29}$ Jean Aubin, no seu pormenorizado estudo sobre as relações de Damião de Góis com o Arcebispo de Upsala, também já fez referência à produção deste códice romano das viagens de Marco Polo. século XVI, sendo perfeitamente normal que Damião de Góis, no seu tempo, conhecesse bem esta fonte.

É sabido que essa obra foi preservada, desde o século XIII, através de três tipos específicos de testemunhos, os franco-italianos; os italiano-venezianos; e os latinos.

Chegaram até à Península Ibérica testemunhos do texto (em cópia), referentes a cada uma dessas três tipologias. A partir de tais testemunhos, esse texto chegou, ainda, à língua portuguesa e à língua castelhana.

Detenhamo-nos, por exemplo, em alguns desses textos e das interpretações sumárias que vieram a permitir por parte de alguns autores. Eva Nilsson Nylander estabelece, de algum modo, uma linha de causa e efeito entre a cópia do texto produzida em Roma por Ioannes Magnus e o texto impresso, c. de 1483-1484, em Gouda, nas Províncias Unidas, com os respectivos trabalhos atribuídos ao tipógrafo Gerardus Leeu, sob o título Delle cose maravigliose del mondo (:latim) De consuetunibus et conditionibus Orientalium regionum. Sabe-se que desta obra é conhecido o exemplar que se conserva na Biblioteca Colombina de Sevilha, no qual foram apostos (e passe a redundânia) interessantes comentários colombinos ${ }^{30}$.

${ }^{30}$ Esta edição quatrocentista é referenciada por F. Craviotto, in Catalogo General de Incunables en Bibliotecas Españolas (2 vols.), vol. II, Madrid, Ministério da Cultura, 1990, vol. II, n. 4712 (II, p. 113). Registe-se ainda que, nas suas Provas de Agregacão (ocorridas em Setembro de 2005 na Universidade de Coimbra), a Prof. Rita Marnoto abordou esta problemática do livro de Marco Polo. Desta autora é também o estudo "Il Marco Paulo di Valentim Fernandes nella catena traslativa del Milione", a ser objecto de edição, em breve, em Itália. Entretanto assinale-se que nos começos de 1998 tínhamos dado por concluídos os trabalhos preparatórios de um nosso vasto trabalho, Marco Paulo. Ho liuro de Nicolao Veneto. Ho trallado da carta de huum genoues das ditas terras (fac-símile da edição lisboeta, por Valentim Fernandes, de 1502, acompanhado da respectiva leitura e notas da nossa responsabilidade), obra essa que visava assinalar a passagem do quinto centenário da referida publicação pós-incunabular portuguesa. Até então tinha sido completada 
Punha-se, pois, a hipótese de que fonte testemunhal se poderá ter servido Ioannes Magnus na realização da sua cópia de Il Milione. Dado que aquele aristocrata sueco redigiu essa sua cópia servindo-se da língua mais internacionalizada da época, o latim, é assim muito mais provável que tenha seguido o testemunho da referida edição latina de Gouda, de c. 1483-1484, do que de uma outra edição (uma das muitas então conhecidas desse texto em Itália), a castelhana intitulada El libro ... d'las cosas maravillosas que vido en las partes orientales, Sevilha, oficina de Juan Varela de Salamanca, numa tradução atribuída a Rodrigo de Santaella, de $1518^{31}$, ou seja, de apenas poucos meses anterior a essa cópia romana de Ioannes Magnus. Entre esses dois textos - o incunabular (de Gouda) e o manuscrito (romano) - situa-se, cronologicamente, a versão portuguesa, com impressão de 1502 em Lisboa, na oficina de Valentim Fernandes de Morávia.

Em fins de 1538 - segundo a mais recente crítica estabeleceu - Damião de Góis voltou de Pádua a terras da Flandres, mais precisamente para a cidade de Lovaina. Para trás tinha ficado a sua enriquecedora acção intelectual, sobretudo em Pádua e Veneza, as amizades que aí tinha feito, bem como algumas outras - as que teve com os irmãos Magnus a que deu novo alento.

a nossa leitura e notas do Livro I da referida obra, até à entrada daquele viajante-aventureiro medieval na cidade de Kambaluc, a capital do império da China. Chegámos a solicitar (por ofício de 9 de Fevereiro de 1998) a S. Exa. o Presidente da República, Dr. Jorge Sampaio, o Alto Patrocínio para esta iniciativa editorial. Esse projecto não passou então, porém, do primeiro dos três livros dessa obra, dada a impossibilidade de, temporalmente, acabarmos então (e nos anos subsequentes), em tempo útil, a leitura diplomática de todo esse testemunho documental das relações luso-asiáticas do século XIII.

31 A presente edição - referenciada por Norton sob o n. ${ }^{\circ} 979$ - surge também indicada por Maria Emília Lavoura, no catálogo Tipografia Espanhola do Século XVI. A Colecção da Biblioteca Nacional, Lisboa, Biblioteca Nacional, 2001, n. 1537 (p. 358).
Quanto às suas relações com o Arcebispo de Upsala e seu irmão Olavus - muito embora outros elementos pudessem ser ainda aqui referidos - essa amizade nunca mais seria esquecida. Passe embora o facto de aquele religioso nunca mais ter voltado à sua prometida diocese da Suécia, vindo a falecer em Roma em 1544, conhece-se a sua actividade na capital pontificia sobretudo através da sua abundante epistolografia (cerca de três dezenas de cartas, duas das quais dirigidas a Damião de Góis, que adiante se publicam).

A permanência daquele prelado em Roma, durante os últimos seis anos da sua vida, é, efectivamente, perspectivada também pelo lado da sua epistolografia. Remete-se, a este respeito, para o Índice que apresentamos como ANEXo II.

Quanto à vida de seu irmão, Olavus Magnus, Damião de Góis, mesmo à distância, não deixará de ter acompanhado, também, pelo menos as facetas mais importantes da sua actividade intelectual. Um dos pontos seguramente mais importantes terá sido - já após o regresso do humanista português a Lisboa - a edição da biografia de Santa Brígida da Suécia (1303-1373) ${ }^{32}$ e de sua filha Santa Catarina de Vadstena, em Roma em 1553, pouco antes de ele mesmo falecer.

Aliás a imprensa incunabular já se havia encarregado de celebrar a primeira daquelas religiosas, inclusivamente por via da edição lubeckiana de Revelationes, em 1492. O papel que esta mulher de virtude veio a ter na história hagiográfica europeia ficou também a dever-se, como a moderna crítica na especialidade hoje reconhece, ao religioso peninsular Alfonso de Jaén, seu contemporâneo e Bispo dessa cidade castelhana, que foi designado pela própria Santa Brí-

\footnotetext{
32 Jean-Marie Maillefer, op. cit., p. 12. Sobre Santa Brígida da Suécia, remetemos, em síntese, para as "entradas" que se apresentam in Omer Englebert, La Fleu des Saints (1979), nova edição, Paris, Albin Michel, 1984, p. 239; e in Gaston Duchet-Suchaux e Michel Pastoureau, La Biblia y los Santos (a partir da edição parisiense de 1990), Madrid, nova edição, Alianza Editorial, 1996, pp. 73-74.
} 

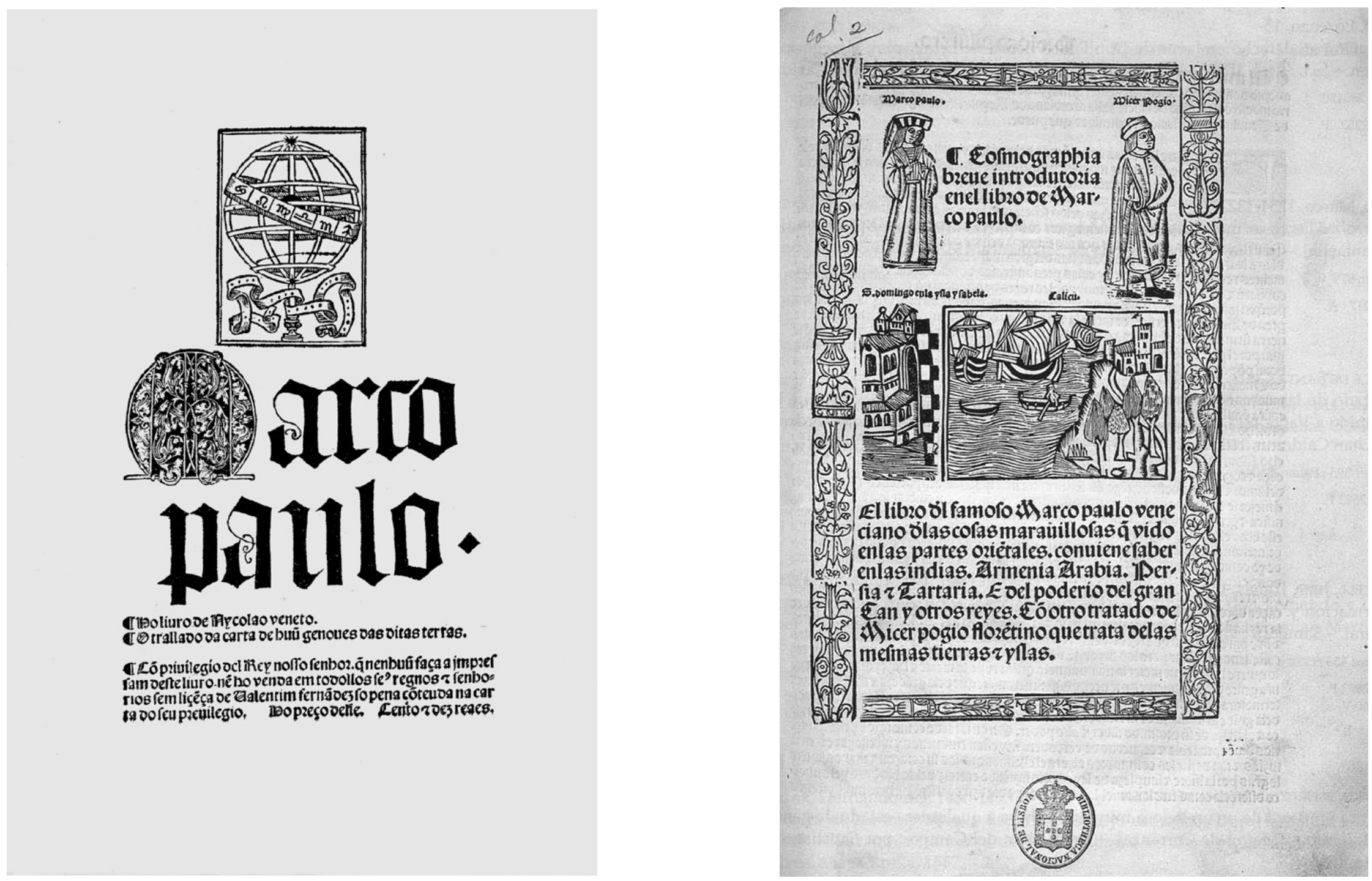

Frontispício do Livro de Marco Paulo, editado em Lisboa, pela oficina de Valentim Fernandes de Morávia em 1502 (à esquerda); e frontispício de El libro d'las cosas maravillosas que vido en las partes orientales, publicado em Salamanca em 1518

$$
\text { (à direita) }
$$


gida da Suécia para preparar uma edição de Revelationes (Liber Celestis) ${ }^{33}$.

Poderia referir-se, em síntese, que enquanto para Olavus Magnus a figura de Santa Brígida da Suécia constituía como que uma figura tutelar, para Damião de Góis - menos dado, embora, a uma tão evidente exteriorização da prática do culto cristão -, uma das figuras que apreciava e respeitava era a do apóstolo Santiago. Ele mesmo se tinha deslocado em peregrinação a Compostela em $1533^{34}$, antes de regressar a Friburgo.

4. Da recepção por Góis, na Flandres, da obra SCHONDIA DE Ziegler E DE UM EVENTUAL EXEMPLAR DA CARTa Gothica

Voltando a Damião de Góis, e tendo este, de Pádua, regressado, como se disse, à cidade de Lovaina, em fins de 1538 ou começos de 1539, casou-se aí com D. Joana van Harguen (logo nesse período inicial do regresso à Flandres). Ele e sua esposa fixaram-se nessa cidade, numa casa da rua Namur ${ }^{35}$,

${ }^{33}$ Remete-se para a obra Alfonso of Jaén. His Life and Works with Critical Editions of the Epistola Solitarii, the Informaciones and the Epistola Serui Christi, por Arne Jonsson, Lund, Lund University Press, col. "Studia Graeca et Latina Lundesia", n. ${ }^{\circ}$ 1, 1989. - Agradecemos à Colega Prof. Brita Larsson ter-nos facultado um exemplar deste estudo sobre este pensador e religioso medieval peninsular.

34 Tratámos sumariamente desta questão no estudo "O culto português a Sant'Iago de Compostela ao longo da Idade Média. Peregrinações de homenagem e louvor ao túmulo e à cidade do Apóstolo entre o séc. XII e o séc. XV”, in Bibliotecas, Arquivos e Museus, Lisboa, vol. I, tomo II, 1986, pp. 521-572 (em separata, mesma numeração).

35 Joaquim de Vasconcelos, Goesiana. Novos Estudos (col. "Renascença Portuguesa-VIII), Porto, 1897, pp. 135-137; Elisabeth Feist Hirsch, Damião de Góis, The Life and the Thought of a Portuguese Humanist (1502-1574), The Hague, Nijhoff, 1967, pp. 113 e 123-128; e Amadeu Torres, I-As Cartas Latinas de Damião de Góis, edição ant. cit. (1982), p. 322. junto à igreja de S. Quintino, vivendo aí praticamente até $1545^{36}$.

Mesmo residindo em Lovaina, os seus interesses e afazeres junto da feitoria de Antuérpia não deixavam, também, de ser uma realidade. Continuou a trabalhar como editor de textos históricos, desenvolvendo - na sequência do esforço dispendido em Pádua e Veneza no âmbito da publicação de textos filosóficos e bíblicos (e que resultara, pelo menos, na edição veneziana de duas obras) - uma obra intelectual de assinalável relevo, voltando a ela mais tarde, já em Lisboa como cronista. Neste aspecto do seu trabalho ele ainda tinha a seu favor o facto de se ter estabelecido uma interessante cumplicidade com um dos mais esclarecidos impressores dessa cidade, Rutgerus Rescius.

Uma das obras que já tinha principiado a preparar em Itália $^{37}$ fora, sem dúvida, aquela a que deu o título de Fides, Religio Moresque. Impunha-se, agora, terminar a sua redacção em Antuérpia.

Aconteceu, porém, que novos dados vieram alterar, então, o seu ritmo de produção desse trabalho. Foi a chegada de elementos acerca dos feitos dos Portugueses no $1 .^{\circ}$ cerco de Diu, ocorrido meses antes, em 1538, e no qual as hostes comandadas por António da Silveira tinham resistido com estoicismo. Assim, estamos em crer que ainda antes de terminar o Fides, Religio Moresque, produziu o texto - e fê-lo chegar ao impressor Rutgerus Réscio - dos Commentarii

\footnotetext{
36 Só foi excepção o período de 1542, em que esteve preso em Paris, na sequência do cerco de Lovaina. A esta matéria voltaremos adiante.

37 No nosso estudo "Damião de Góis e as línguas orientais. Algumas dúvidas e acertos", in Congresso Internacional Damião de Góis na Europa do Renascimento. Actas, Braga, Publicações da Faculdade de Filosofia, Universidade Católica Portuguesa, 2003, pp. 817-842, registamos (por exemplo, in p. 835) que, ainda em Pádua, o humanista português recebera, de Zaga Zabo, uma epístola com um texto em caracteres etíopes que veio a utilizar, já na edição flamenga de 1540, na sua obra Fides, Religio Moresque.
} 


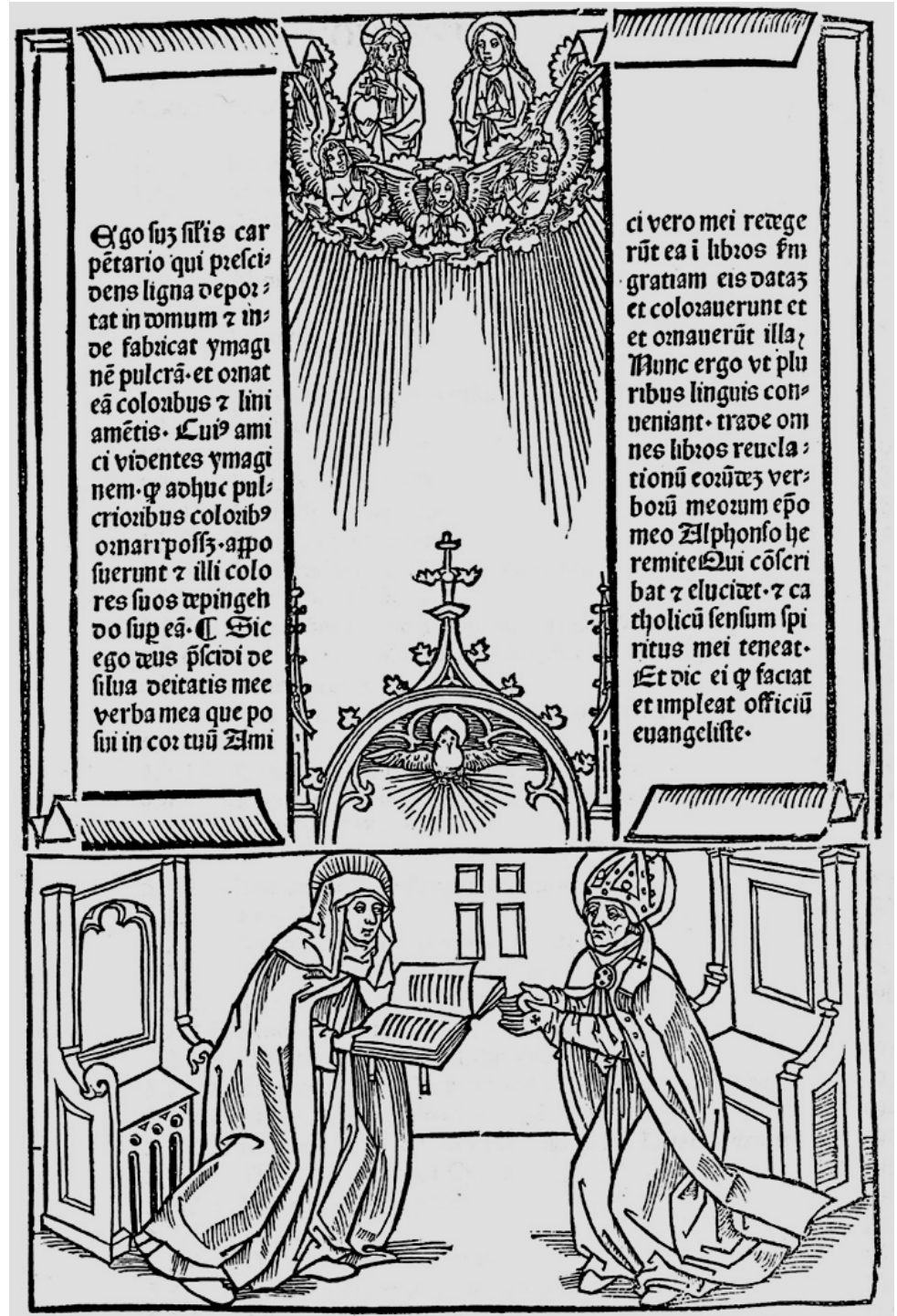

Frontispício de Revelationes, por Santa Brígida, na edição de Lubech, 1492, à esquerda; e gravura representando a mesma santa da Suécia, in Heures de Boucicaut, séc. XV (Paris, Musée Jacquemart-André), à direita

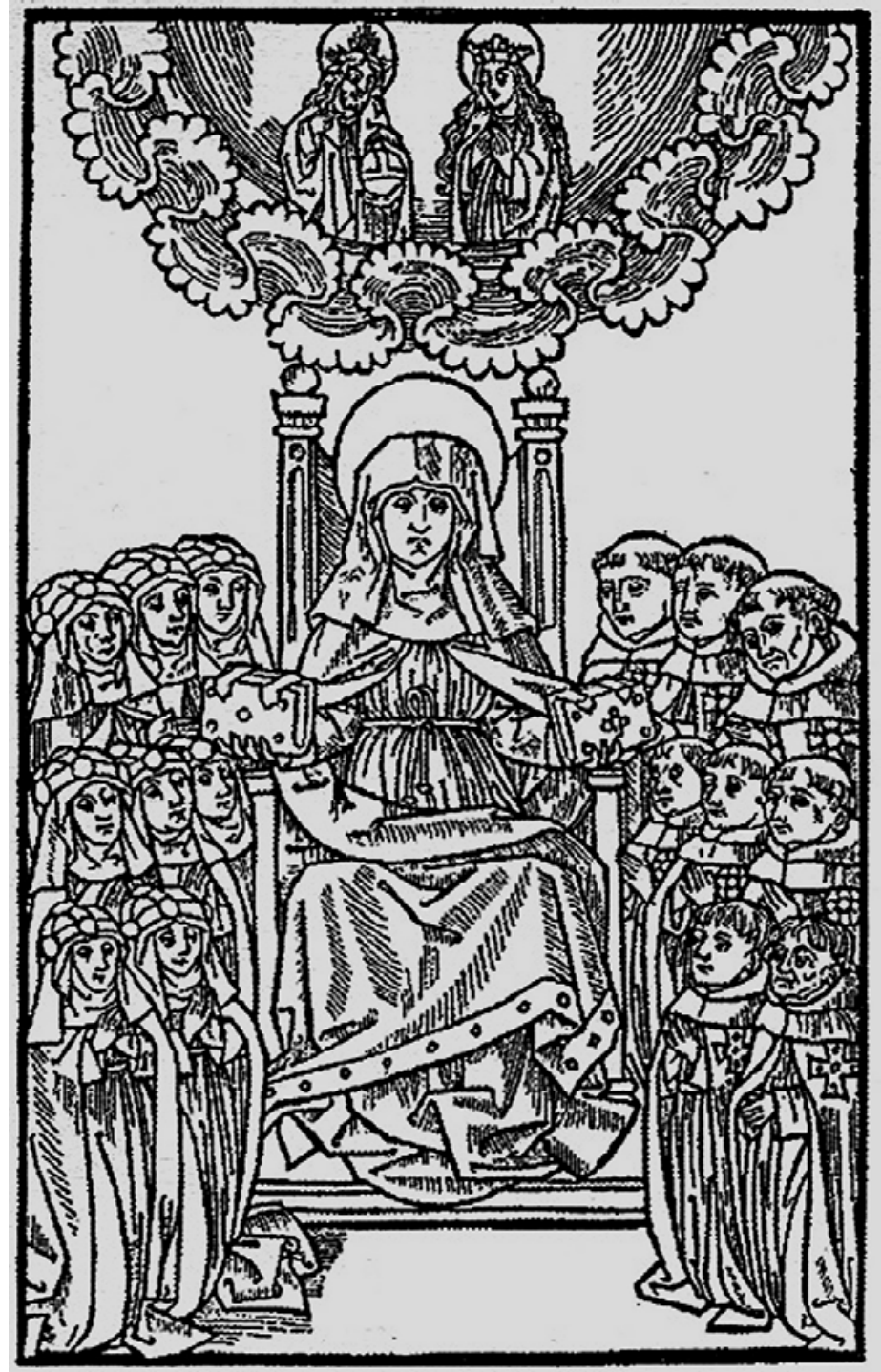


Rerum Gestarum in India ${ }^{38}$, acerca dos referidos eventos bélicos no Golfo de Cambaia.

Durante a preparação do Fides..., o humanista português sentiu a necessidade de aprofundar (como já se disse atrás) as linhas de proximidade, em vários contextos, entre as regiões da Etiópia e as nórdicas, em particular a Lapónia. Pode considerar-se que o cerne das suas preocupações não eram apenas problemas de incidência geográfica mas, também, outras relacionadas com a expansão da fé cristã para ambos os territórios em estudo.

Nesse sentido Góis tinha na sua casa de Lovaina (a aludida residência na rua de Namur) uma interessante biblioteca que foi enriquecendo de dia para dia. Assim, a algumas obras históricas que privilegiadamente lia - como a já múltiplas vezes referenciada Novus Orbis (Basileia, 1532) - vieram a juntar-se algumas outras cuja leitura lhe permitiram que este seu trabalho editorial de 1540 tivesse a consistência documental que verdadeiramente tem.

Uma delas foi a já atrás referida edição de Schondia, por Ziegler, editada em Estrasburgo em 1532. As pesquisas de Jean Aubin vieram provar, de forma segura, que na preparação do seu texto sobre a descrição da Lapónia, mais do que referenciada, foi seguida (parcialmente transcrita) com particular meticulosidade, num período em que os direitos de autor não apresentavam a configuração jurídica dos nossos dias.

38 Tendo sido publicada, primeiramente, nessa cidade de Lovaina, na referida oficina de Rutgerus Rescius, nesse mesmo ano seria ainda objecto de uma edição em Itália (admitindo-se que em Veneza); no ano seguinte, por seu lado, este seu texto seria vertido para a língua alemã, beneficiando de uma edição em Augsburgo. Américo da Costa Ramalho, na colectânea de estudos Oriente-Ocidente, mais precisamente no seu trabalho "Damião de Góis e os Humanistas Portugueses", pp. 429-441, estabelece (p. 432) que se pode "verificar um real progresso estilístico da primeira para a segunda edição".
À medida que aprofundava os seus conhecimentos culturais e espirituais sobre a Lapónia, tornou-se-lhe necessário, de igual modo, conhecer a especificidade geográfica desse território. Estamos em crer, deste modo, que ou conseguiu que de Veneza lhe chegasse um exemplar da também já referenciada Carta Gothica ou Carta Marina de Olavus Magnus, ou, em alternativa, pôde consultá-la em alguma instituição, particular ou pública, dessa sua cidade de acolhimento.

Quanto à primeira dessas premissas, tal aquisição era possível, por exemplo, através de qualquer livreiro de Lovaina ou de Antuérpia. Não dispomos, apesar de tudo, de matéria epistolar coeva que elucide da oferta de um exemplar desse trabalho e dos respectivos comentários impressos, pelo seu autor, ao humanista e diplomata português ${ }^{39}$.

\section{Dos interesses plurais de um bibliógrafo e erudito} E OS SEUS CAMINHOS "DO LIVRO À LIVRARIA"

Enquanto isso, nesse período da sua permanência em Lovaina até 1545 , a sua acção como estudioso tornou-se extensiva a outras áreas. Foi o caso da reunião de outras fontes como por exemplo algumas relacionadas com os estudos geográficos de Sebastião Munster, em relação à Península Ibérica em particular.

Uma das outras obras de que possuiu então um exemplar, estamos certos, foi a organizada por Sebastianus Munster, Geographia Vniversalis, Tum Vetus Et Nova, Complectens Claudii Ptolemaei Alexandrini Enarrationis Libros VIII. (...) Succedunt

\footnotetext{
${ }^{39}$ Uma pesquisa atenta sobre o epistolário de Ioannes Magnus para outras entidades com quem se relacionou - seguindo para esse efeito a criteriosa (mesmo que incompleta) edição de Brita Larsson - não permite concluir pela abundante oferta de exemplares dessa carta geográfica aos seus correspondentes.
} 
Tabulae Ptolemaice, Opera Sebastiani Munster Mouo Paratae modo. His Adiectae Sunt Plurime Nouae Tabulae, de Basileia, da oficina de Henricum Petrum, 1540. Desta edição se veio a servir na preparação da sua Hispania ${ }^{40}$, ainda de Lovaina (e mesmo impressor), de 1542.

Trabalhou ainda então nessa cidade, de igual modo, a coligir elementos acerca dos tumultuosos acontecimentos do cerco de Lovaina e das suas lamentáveis consequências em termos pessoais. Esse seu esforço não passaria então, porém, a letra de forma, o que só viria a suceder, já após o seu regresso a Lisboa, em meados dessa década de quarenta, quando em 1546 o impressor Luís Rodrigues se disponibilizou a fazê-lo ${ }^{41}$.

Pelo exposto pode concluir-se que Damião de Góis, no período de cerca de seis anos - já descontados os meses da ausência forçada do seu cativeiro em França, na sequência do cerco de Lovaina de $1542^{42}$ - desenvolveu uma proficua actividade intelectual nessa permanência na cidade de Lovaina com esse trabalho de natureza editorial e crítica, a sua extensa epistolografia e os estudos ${ }^{43}$ que levou a cabo na alma-mater de Lovaina.

Perspectivando-se os livros que, neste período da sua vida em Lovaina, foram constituindo a sua biblioteca pessoal, pode considerar-se que Damião de Góis, com a produção

40 Esta matéria virá a ser objecto das nossas reflexões e edição no volume Obras de Damião de Góis, vol. III, que à presente data temos em preparação.

${ }^{41}$ Remete-se para a edição Damiani Gois Equitis Lusitani. Urbis Lovaniensis (sic) Obsidio, Lisboa, oficina de Luís Rodrigues, 1546, [24] fls.

${ }_{42}$ Recorde-se, no elenco de documentos que se reportam à participação de Góis naqueles acontecimentos de Lovaina, que o discurso do humanista português, perante aquela Universidade, apresenta o título "Ad Amplissimum Almae Universitatis Lovaniensis Collegium"; e que o relato de Góis a Carlos V acerca do cerco de Lovaina e suas consequências foi editado in Schardius Redivivus sive Rerum Germanicarum Scriptores (Giessen, 1673), vol. II, pp. 620-631, seguindo nós aqui as indicações, a este respeito, produzidas por E. F. Hirsch.

43 A estes estudos também faz referência Elisabeth Feist Hirsch, op. cit. (no referido cap. 8). das obras referidas, foi um empenhado produtor de texto. Importa estabelecer, assim, não existir uma área de separação muito nítida, em termos ideológicos, que permita distanciar o produtor de texto do produtor do livro e alimentador dos respectivos espaços de usufruição/consumo dos mesmos.

Na cidade de Estrasburgo - onde em 1532 tinha sido produzida a edição impressa da obra Schondia, de Ziegler (a qual, voltamos a recordar, esteve em posse de Góis) - esta matéria do espaço de confluência de produção de texto e do espaço de produção do livro foi objecto de recentes e pertinentes considerações por parte do filósofo Jean-Luc Nancy. Segundo este autor, "o livro imprime o carácter de uma voz, que ele compõe, o tipo ou a tipografia de uma modulação vocal, de uma palavra" 44 .

Para este pensador francês, amigo de Jacques Derrida, falando do fim em si do livro - e aplicamos, aqui, tais premissas a Damião de Góis como produtor de livros (nesta sua fase de Lovaina) -, a essência da impressão do livro "consiste na comunicação, na ressonância e na disseminação até à dispersão, até à metamorfose e à reinterpretação - de uma voz, de uma oralidade irredutível: a diferença de uma entoação" 45 .

Damião de Góis, como produtor de texto - leia-se, pois, como produtor do livro -, é o criador de uma mercadoria espiritual. O agente comercial e o diplomata - ao serviço da Corte portuguesa, que dele esperava, inclusivamente, uma redinamização na Europa de leste do comércio das especiarias (chegadas a Lisboa vindas do Oriente) - é, nestes termos, a voz da escrita, a voz do texto e, em última instância, em termos hiperbólicos, a voz activa e não distanciada da consciência dos descobrimentos portugueses.

${ }^{44}$ Jean-Luc Nancy, Du livre et de la librairie, Estrasburgo, por encomenda da livraria Quai des Brumes, dessa cidade, edição de La Fosse aux Ours, 2004 45 Idem, ibidem. 


\section{Anexo I}

EPISTOLÁRIO DE IOANNES MAGNUS, DE ROMA, VICENZA E VENEZA $(1538-1540)^{46}$

\begin{tabular}{|c|c|c|c|}
\hline $\mathrm{N}^{\mathrm{o}}$ & Data & Lugar & Dirigida a \\
\hline 1. $(29)$ & 153813 Janeiro & Roma & $\begin{array}{l}\text { Duque Henrique Jr. de } \\
\text { Brunswick e Luneburg }\end{array}$ \\
\hline 2. $(30)$ & 1538 28 Janeiro & Roma & Johannes Dantiscus \\
\hline 3. (31) & 153814 Maio & Vicenza & Cardeal Aleander \\
\hline 4. $(32)$ & 153827 Maio & Vicenza & $\begin{array}{l}\text { Cardiais Campeggio, } \\
\text { Simoneta e Brupdusinus }\end{array}$ \\
\hline 5. (33) & 153830 Maio & Vicenza & Johannes Dantiscus \\
\hline 6. (34) & 153830 Maio & Vicenza & $\begin{array}{l}\text { Magistrado superior e } \\
\text { conselheiros de Gdansk }\end{array}$ \\
\hline 7. (35) & 153820 Dezembro & Veneza & Johannes Dantiscus \\
\hline 8. (36) & 153822 Dezembro & Veneza & $\begin{array}{l}\text { Magistrado superior e } \\
\text { conselheiros Gdansk }\end{array}$ \\
\hline 9. (37) & 153913 Julho & Veneza & Johannes Dantiscus \\
\hline 10. (38) & 154020 Outubro & Veneza & Paul III \\
\hline
\end{tabular}

46 Cfr. Brita Larsson, Johanne's Magnus' Latin Letters. A Critical Edition with Introduction and Commentary, edição ant. cit. (1992), p. 192. Indicam-se neste documento, tal como no seguinte, à frente da nossa numeração, a numeração constante da mesma epistolografia na obra de Brita Larsson que aqui seguimos e a quem agradecemos a deferência de nos ter autorizado quanto à reprodução deste passo das suas pesquisas. Apenas acrescentámos as duas cartas enviadas por Johannes Magnus, de Roma, para Damião de Góis.

\section{Anexo II}

EPISTOLÁRIO DE IOANNES MAGNUS, 1541-1544, DE ROMA (1541-1544) ${ }^{47}$

\begin{tabular}{|c|c|c|c|}
\hline$N^{\circ}$ & Data & Lugar & Dirigida a \\
\hline 1. (39) & 154114 Fevereiro & Roma & Johannes Dantiscus \\
\hline 2. $(--)$ & 15411 Abril & Roma & Damianus a Goes \\
\hline 3. $(40)$ & 1541 Abril & Roma & Antonius de Salamancha \\
\hline 4. (41) & 15417 Julho & Roma & $\begin{array}{l}\text { Cardeal Marcello } \\
\text { Cervino }\end{array}$ \\
\hline 5. (42) & 15417 Julho & Roma & Cardeal Pietro Bembo \\
\hline 6. (43) & 154113 Julho & Roma & $\begin{array}{l}\text { Cardeal Marcello } \\
\text { Cervino }\end{array}$ \\
\hline 7. (44) & 154117 Agosto & Roma & $\begin{array}{l}\text { Cardeal Marcello } \\
\text { Cervino }\end{array}$ \\
\hline 8. $(45)$ & 154118 Agosto & Roma & Bispo Durante \\
\hline 9. (46) & 15413 Setembro & Roma & Johannes Dantiscus \\
\hline 10. (47) & 15414 Setembro & Roma & Cardeal Ferreri \\
\hline 11. (48) & 154117 Setembro & Roma & Hieronymus Quirinus \\
\hline 12. (49) & 154117 Setembro & Roma & Johannes Mattheus \\
\hline 13. $(50)$ & 154220 Abril & Roma & Johannes Cochleus \\
\hline 14. (51) & $1542 ?$ & Roma & Segismundo I \\
\hline 15. (52) & 154230 Junho & Roma & Hieronymus Quirinus \\
\hline 16. (53) & 154228 Julho & Roma & Cardeal Pietro Bembo \\
\hline 17. (54) & 15425 Setembro & Roma & $\begin{array}{l}\text { Cardeal Marcello } \\
\text { Cervino }\end{array}$ \\
\hline 18. (55) & 154212 Novembro & Roma & $\begin{array}{l}\text { Cardeal Rudolfo Pio de } \\
\text { Carpi }\end{array}$ \\
\hline 19. (56) & 154217 Novembro & Roma & Phillipus Archintus \\
\hline 20. (57) & 1542 Dezembro & Roma & Johannes Mattheus \\
\hline 21. (58) & 154316 Fevereiro & Roma & Paulo III \\
\hline
\end{tabular}




$\begin{array}{llll}\text { 22. (59) } & 1543 \quad 8 \text { Março } & \text { Roma } & \text { Paulo III } \\ \text { 23. (60) } & 1543 \text { ? } & \text { Roma } & \begin{array}{l}\text { Leandro de Albertis } \\ \text { 24. (61) }\end{array} 1543 \text { ? } \\ & & \text { Roma } & \begin{array}{l}\text { Johannes Baptista } \\ \text { Rhamusio }\end{array} \\ \text { 25. (- -) } & \text { 1543 21 Maio } & \text { Roma } & \text { Damianus a Goes } \\ \text { 26. (62) } & 1543 \text { Outubro } & \text { Roma } & \text { Segismundo I } \\ \text { 27. (63) } & 1543 \text { Outubro } & \text { Roma } & \text { Bispo de Plocz } \\ \text { 28. (64) } & 1544 \text { Janeiro } & \text { Roma } & \text { Paulo III } \\ \text { 29. (65) } & 1544 \text { 4 Março } & \text { Roma } & \text { Paulo III }\end{array}$

\section{ESTUDOS CAMONIANOS EM ITÁLIA*}

\section{Gianluca Miraglia}

ENTRE AS NUMEROSAS PUBLICAÇÕES vindas à luz em 1972, por ocasião do IV centenário da editio princeps de Os Lusíadas, destaca-se, no âmbito dos estudos sobre a difusão da obra de Camões no mundo, o livro de G. Manuppella, Camoniana Itálica ${ }^{1}$ É um levantamento bibliográfico amplo, minucioso e exaustivo que abrange a crítica literária, a criação poética e narrativa, o teatro, as artes e a música, repercorrendo a presença e a recepção do poeta quinhentista na cultura italiana ao longo dos séculos. Passados aproximadamente trinta anos, é altura certa para, em jeito de addenda, dar breve notícia, que não se pretende porém completa, dos estudos camonianos em Itália, dando a esta expressão um sentido mais lato que engloba todos os artigos de autores italianos editados nas últimas três décadas, independentemente do seu local de publicação.

Seguindo a ordem cronológica, podemos começar pelo ano de 1975, ano em que J.V. de Pina Martins organizou em Roma uma importante exposição bibliográfica, que teve

* O texto reproduz, com actualização bibliográfica, a comunicação apresentada no IX Fórum Camoniano: 1. A projecção universal de Camões, 2. O ensino de Camões hoje, Centro Internacional de Estudos camonianos da Associação da Casa-Memória de Camões em Constância, 26 e 27 de Julho de 2001.

${ }^{1}$ Camoniana Itálica: subsídios bibliográficos, Coimbra, Instituto Estudos Italianos, 1972. 